\title{
Analysis of Therapeutic Effect of Cuff Repair with Arthroscopic Double Row Suture-bridging
}

\author{
Yi Zou \\ Department of Orthopaedics, The Second Hospital of Jingzhou, Jingzhou, Hubei Province,434020, China.
}

Keywords: arthroscopy; double row suture-bridging; rotator cuff injury; curative effect

\begin{abstract}
To explore the effect of arthroscopic double-row suture-bridging on rotator cuff injury, a comparative study of 70 patients with rotator cuff injuries treated in the Second Hospital from July 2015 to April 2017 was conducted. The patients were randomly divided into two groups according to the digital table, that is, the control group of 35 patients underwent arthroscopic single row suture-bridging, and the analysis group of 35 patients underwent arthroscopic double row suture-bridging. And the paper summarizes and contrasts the effects of the two kinds of surgical treatment after data analysis in SPSS 21.0 statistical software. Results show that there was no significant difference in shoulder activity, visual analogue scale (VAS), UCLA score and Constant score before treatment ( $\mathrm{P}>0.05)$. After treatment, except the VAS score difference has no statistical significance $(\mathrm{P}>0.05)$, other scores in the analysis group improved significantly are beyond the control group $(\mathrm{P}<0.05)$. Therefore, the double row suture-bridging technique under the shoulder arthroscopy is effective in the treatment of rotator cuff injuries. It is helpful to improve the clinical curative effect and improve the joint function in the early stage, which has the value of clinical popularization and application.
\end{abstract}

In recent years, arthroscopy has developed rapidly in clinical practice in China, providing an important guarantee for the treatment of rotator cuff injuries in clinical diseases. It has been reported in the existing reports that the double row suture-bridging by shoulder arthroscopy can be applied to achieve desirable curative effect of rotator cuff injury. In view of this, a comparative study of 70 patients with rotator cuff injuries treated in this hospital from July 2015 to April 2017 was conducted to explore curative effect of the arthroscopic double row suture-bridging treatment on rotator cuff injury, and to provide a reference for the clinical treatment of the disease. Summarized as follows:

\section{DATA AND METHODS}

\subsection{General data}

In this study, 70 patients with rotator cuff injury treated in our hospital from July 2015 to December 2016 were enrolled in a comparative study. Inclusion criteria: patients were admitted to hospital for X-ray and magnetic resonance imaging; this study was authorized by the hospital ethics committee, patients and their families were informed and voluntarily signed the consent form; Exclusion criteria: (1) having previous history of shoulder surgery; (2) patients also having arthritis, nerve injury, shoulder joint inflammation and other pathology; (3) patients with mental illness, language problems, and the hearing impaired; (4) patients unaware of the contents of this study.

The patients were randomly divided into the control group and the analysis group, 35 cases each. The patients in the control group were 20 males and 15 females aged 30 to 80 years with a mean age of ( $50.3 \pm 5.2)$ years, and a duration of 5 days to 3 years with an average duration of $(1.5 \pm 0.5)$ years. The follow-up time ranged from 5 to 12 months (mean $8.3 \pm 2.1$ months) after operation. The analysis group consisted of 18 males and 17 females, aged from 30 to 80 years (mean age, $51.1 \pm 5.6$ years), and a duration of 5 days to 3 years with an average duration of $(1.8 \pm 0.6)$ years. The average follow-up time ranged from 5 to 12 months after operation, with an average of $(8.5 \pm 1.8)$ months. There was no significant difference in general data between the two groups ( $>0.05)$, thus comparable. 


\subsection{Method}

The control group underwent shoulder arthroscopic single row suture-bridging; the analysis group double row suture-bridging. Which included: perform tracheal intubation general anesthesia program, and the patient take lateral position on the healthy side tilting back $30^{\circ}$. Using position frame to fix the patients' position, and during the surgery, corresponding antihypertensive treatment was used to maintain the systolic blood pressure at $9 \sim 100 \mathrm{mmHg}$. Followed by the preparation of working path under arthroscopy, explore the humeral joint structure through the outside access, the anterior approach, the lateral approach, observe the performance of biceps lip, long tendon, articular cartilage, rotator cuff fulcrum. And locate the rotator cuff injury in a timely manner to deal with glenohumeral joint lesions. Then perform the subacromial arthroscopic induction, clean up the subacromial bursa, decompress the anterolateral acromial angle subacromial, increase the subacromial space Evaluate the rotator cuff tear, such as the degree of tearing, size, etc., release the tendon and clean the stump, and then remove the tubercle tuberosity sclerosis bone, so that the bone bed is fresh, and then implanted the Smith \& Nephew inner line anchor $(45 \mathrm{~mm})$ outside of the cartilaginous margin, and suture rotator cuffs with the "thread-passing mattress" mode, make a knot on the surface of the rotator cuff. The tear-edge of the rotator cuff was fixed to the proximal end of the bone-bed and finally fix the fixed knot through the Xerox Fai external drainage anchor and fix it to the outer side of the large nodule. Adjust the tension of the wire and tighten the nut to fix the rotator cuff.

\subsection{Efficacy criteria}

(1)Visual analogue score (VAS) was used to evaluate the pain scores before and after treatment in both groups. With a total score of 10 points, the higher the score, the more severe the pain. (2) Shoulder function was evaluated using the Constant Rating Scale and the Shoulder Function Score System (UCLA), Constant score scale involves a total of three dimensions of pain, daily living, and active range, 100 points in total; the UCLA total score is 35 points, the higher the score, the better the functional recovery; (3) shoulder joint range of motion was assessed from flexion and outreach degree.

\subsection{Statistical methods}

Data processing of the study was completed with SPSS 21.0 statistical software, where $\mathrm{P}<0.05$ means there is a significant statistical difference; of which the normal distribution of measurement data were tested using independent samples.

\section{RESULTS}

\subsection{Shoulder range of motion differences before and after treatment in the two groups}

There was no significant statistical difference in the range of motion of the shoulder between the two groups before treatment $(\mathrm{P}>0.05)$, and after treatment, both were improved. Compared with the control group, the improvement effect of the analysis group was significantly better $(\mathrm{P}<0.05)$.

Table 1 Shoulder range of motion differences before and after treatment in the two groups $(\bar{x} \pm s)$

\begin{tabular}{cccccc}
\hline \multirow{2}{*}{ Group } & $\mathrm{n}$ & \multicolumn{2}{c}{ Flexion range of motion $\left(^{\circ}\right)$} & \multicolumn{2}{c}{ Outreach range of motion $\left(^{\circ}\right)$} \\
\cline { 3 - 6 } & & Before treatment & After treatment & Before treatment & After treatment \\
\hline $\begin{array}{c}\text { Analysis group } \\
\text { (1) }\end{array}$ & 35 & $107.3 \pm 35.1$ & $169.2 \pm 18.7$ & $111.3 \pm 37.6$ & $163.3 \pm 17.4$ \\
$\begin{array}{c}\text { Control group } \\
\text { (2) }\end{array}$ & 35 & $106.9 \pm 34.9$ & $141.4 \pm 19.32$ & $109.9 \pm 38.1$ & $143.8 \pm 18.3$ \\
$t_{\text {In the group }} / \mathrm{P}$ & $/$ & $119.21 /<0.05$ & (2) $5.12 /<0.05$ & $(1) 7.43 /<0.05$ & $(2) 4.74 /<0.05$ \\
$t_{\begin{array}{c}\text { Between the } \\
\text { group } / \mathrm{P}\end{array}}$ & $/$ & $0.05 />0.05$ & $6.11 /<0.05$ & $0.15 />0.05$ & $4.57 /<0.05$ \\
\hline
\end{tabular}

\subsection{Score differences between the two groups before and after treatment}

There was no significant difference in visual analog scale (VAS), UCLA score and constant score between the two groups before treatment $(\mathrm{P}>0.05)$, and after treatment, both were improved. The 
improvement of UCLA score and constant score of the analysis group was significantly better than that of the control group $(\mathrm{P}<0.05)$, while the VAS score difference was not statistically significant ( $>$ 0.05) (Table 2).

Table 2 The score differences between the two groups before and after treatment $(\bar{x} \pm s)$

\begin{tabular}{|c|c|c|c|c|c|c|c|}
\hline \multirow[b]{2}{*}{ Group } & \multirow[b]{2}{*}{ Cases } & \multicolumn{2}{|c|}{ VAS score (points) } & \multicolumn{2}{|c|}{ UCLA score (points) } & \multicolumn{2}{|c|}{ Constant score (points) } \\
\hline & & $\begin{array}{l}\text { Before } \\
\text { treatment }\end{array}$ & $\begin{array}{c}\text { After } \\
\text { treatment }\end{array}$ & $\begin{array}{l}\text { Before } \\
\text { treatment }\end{array}$ & $\begin{array}{c}\text { After } \\
\text { treatment }\end{array}$ & $\begin{array}{l}\text { Before } \\
\text { treatment }\end{array}$ & $\begin{array}{c}\text { After } \\
\text { treatment }\end{array}$ \\
\hline $\begin{array}{l}\text { Analysi } \\
\text { s group } \\
\text { (1) }\end{array}$ & 35 & $5.47 \pm 1.29$ & $2.35 \pm 0.55$ & $15.47 \pm 5.30$ & $33.40 \pm 5.48$ & $\begin{array}{c}51.33 \pm 16.0 \\
1\end{array}$ & $\begin{array}{c}80.41 \pm 15.9 \\
1\end{array}$ \\
\hline $\begin{array}{l}\text { Control } \\
\text { group } \\
\text { (2) }\end{array}$ & 35 & $5.44 \pm 1.25$ & $2.30 \pm 1.01$ & $15.62 \pm 5.40$ & $21.36 \pm 5.31$ & $\begin{array}{c}50.98 \pm 16.3 \\
5\end{array}$ & $\begin{array}{c}62.35 \pm 13.2 \\
5\end{array}$ \\
\hline $\begin{array}{l}t_{\text {In the }} \\
\text { group } / \mathrm{P}\end{array}$ & / & $17.04 /<0.05$ & $\begin{array}{c}2 \\
7.88 /<0.05\end{array}$ & $\begin{array}{c}1 \\
13.91 /<0.05\end{array}$ & $\begin{array}{c}2 \\
4.48 /<0.05\end{array}$ & $\begin{array}{c}1 \\
7.62 /<0.05\end{array}$ & $\begin{array}{c}2 \\
3.20 /<0.05\end{array}$ \\
\hline $\begin{array}{l}\text { Between } \\
\text { the } \\
\text { group } / \mathrm{P}\end{array}$ & / & $0.10 />0.05$ & $1.35 />0.05$ & $0.12 />0.05$ & $9.33 /<0.05$ & $0.09 />0.05$ & $5.16 /<0.05$ \\
\hline
\end{tabular}

\section{DISCUSSIONS}

The shoulder cuff often undergo wearing by the shoulder acromioclavicular ligament. It can be seen from the anatomical structure and withstand mechanical stress that the site of rotator cuff is a weak point. The shoulder joint is prone to rupture when abrupt adduction is conducted at extended position. And due to limb gravity and the pull of the shoulder sleeve, the gap will get bigger and bigger and not easy to heal ${ }^{[1-3]}$. The main clinical manifestations of the patients are pain, pressing pain, active motor disorders, and with the course of the disease extend to 3 months, shoulder joint adhesions can be seconded, resulting in active and passive mobilization limitation ${ }^{[4,5]}$.

In the treatment of rotator cuff injuries, double row suture-bridging technology works mainly by maintaining the affected joints tendons and bone surface pressure and maximizing the contact area stability ${ }^{[6-8]}$. It has been reported in the literature ${ }^{[9]}$ that the double row suture-bridging technique can rebuild a larger area of the rotator cuff footprints than single row fixed sutures. And it helps to reduce the formation of footprints lacuna and thus enhances the uniformity of the footprints tension, achieving a better early fixation effecs.t, and more in line with biomechanical characteristic from the results of this study, there was no significant difference in shoulder activity, visual analogue scale (VAS), UCLA score and constant score before treatment ( $>$ > 0.05). After treatment, both were improved except for the VAS score difference has no statistical significance $(\mathrm{P}>0.05)$, other scores in the analysis group improved significantly beyond the control group $(\mathrm{P}<0.05)$. This shows that double row suture-bridging technology will not increase the patient's pain score, while more conducive to improving patients symptoms of the joint and promote early function recovery. It is also needed to note that in the repair process of rotator cuff injury, the rotator cuff may be teared again often due to poor quality of tendon tissue, improper healing training methods and amount, suture anchor prolapse, suture rupture and other reasons. Studies have shown that ${ }^{[10]}$, in order to prevent secondary rupture of rotator cuff, attention should payed to knotting row anchor, and suture should not be too tight, and anchor spacing should be based on the size of the patient's wounds.

In summary, the arthroscopic double row suture-bridging technology for rotator cuff injury repair does have a good effect, and helps to improve clinical efficacy as well as the early improvement of patients' joint function, thus having clinical application value.

\section{REFERENCES}

[1] Hantes ME1, Ono Y2, Raoulis VA1, Doxariotis N1, Venouziou A1, Zibis A1, Vlychou M3, 
"Arthroscopic-Single-Row Versus Double-Row Suture Bridge Techni-que for Rotator Cuff Tears in Patients Younger Than 55 Years: A Prospective Comparative Study”, Am J Sports Med, 2017.

[2] Abdelshahed M, Mahure SA, Kaplan DJ, Mollon B, Zuckerman JD, Kwon YW, Rokito AS, "Arthroscopic Rotator Cuff Repair: Double-Row Transosseous Equ-ivalent Suture Bridge Technique”, Arthrosc Tech,2016.

[3] Virk MS, Bruce B, Hussey KE, Thomas JM, Luthringer TA, Shewman EF, Wang VM, Verma NN, Romeo AA, Cole BJ, "Biomechanical Performance of Medial Row Suture Placement Relative to the Musculot-endinous Junction in Transosseous Equivalent Suture Bridge Double-Row Rotator Cuff Repair”, Arthroscopy, vol.02, pp.242-250,2017.

[4] Jaeger M, Berndt T, Rühmann O, Lerch S,"Patients With Impingement Syndrome With and Without Rotator Cuff Tears Do Well 20 Years After Arthroscopic Subacromial Decompression”,Arthroscopy,vol.04,pp.246-251,2017.

[5] Lo IK, Parten PM, "Burkhart SS. Combined subcoracoid and subacromial impingement in association with anterosuperior rotatorcuff tears: An arthroscopic approach”, Arthroscopy, vol.10, pp.1068-78,2003.

[6] Parnes N, Bartoszewski NR, Defranco MJ "Arthroscopic Repair of Rotator Cuff Tears in Active Patients Younger Than 40 Years: 2- to 5-Year”, Orthopedics, vol.20, pp.1-6,2017.

[7] Teratani T."Comparison of epidemiology and outcomes of arthroscopic rotator cuff repair for anterosuperior and posterosuperior rotator cuff tears”,J Orthop. Vol.04, pp.430-433,2014.

[8] Hashiguchi H, Iwashita S, Okubo A, Takai S, “Arthros-copic Removal and Tendon Repair for Refractory Rotator Cuff Calcific Tendinitis of the Shoulder",J Nippon Med Sch,vol.02,pp,119-24,2017.

[9] Kim KC, Rhee KJ, Shin HD, "Deformities associated with the suture-bridge technique for full-thickness rotator cuff tears”, Arthroscopy, vol.11, pp. 1251-7,2008.

[10] Werthel JD, Pelissier A, Massin P, Boyer P, ValentiP, “Arthroscopic double row cuff repair with suture-bridging and autologous conditioned plasma injection: Functional and structural results”, J Shoulder Surg. Vol.04, pp.101-6,2014. 